\title{
Differential expression of coxsackievirus and adenovirus receptor in endomyocardial tissue of patients with myocarditis
}

\author{
GUSTAVO E. GARCÍA-BECERRIL ${ }^{1 *}$, ANÍBAL E. CRUZ-MONTALVO ${ }^{2 *}$, \\ MIGUEL A. DE LA CRUZ ${ }^{3}$, MIGUEL A. ARES ${ }^{3}$, LUIS A. MORENO-RUIZ ${ }^{4}$, ADDA J. GARCÍA-CHEQUER ${ }^{5}$, \\ CARMEN MALDONADO-BERNAL ${ }^{6}$, LUZ M. GÓMEZ-JIMÉNEZ ${ }^{7}$, CESAR A. FLORES-GARCÍA ${ }^{8}$, \\ MARTÍN H. GARRIDO-GARDUÑO ${ }^{1}$ and MARÍA G. CÁRDENAS-MONDRAGÓN ${ }^{3}$
}

${ }^{1}$ Clínica de Insuficiencia Cardiaca; ${ }^{2}$ Unidad de Cuidados Intensivos Cardiovasculares, UMAE Hospital de Cardiología del Centro Médico Nacional Siglo-XXI, Instituto Mexicano del Seguro Social; ${ }^{3}$ Unidad de Investigación Médica en Enfermedades Infecciosas y Parasitarias, UMAE Hospital de Pediatría 'Dr. Silvestre Frenk Freund', Centro Médico Nacional Siglo-XXI, Instituto Mexicano del Seguro Social; ${ }^{4}$ Servicio de Hospitalización Adultos, UMAE Hospital de Cardiología del Centro Médico Nacional Siglo-XXI, IMSS; ${ }^{5}$ Laboratorio en Biología del Desarrollo, Unidad de Hemato-Oncología e Investigación del Hospital Infantil de México, 'Federico Gómez', Secretaria de Salud;

${ }^{6}$ Laboratorio de Investigación en Inmunología y Proteómica, Hospital Infantil de México, ‘Federico Gómez',

Secretaria de Salud; ${ }^{7}$ Servicio de Patología UMAE Hospital de Especialidades del Centro Médico Nacional Siglo-XXI, Instituto Mexicano del Seguro Social; ${ }^{8}$ Servicio de Patología, UMAE Hospital de Cardiología del Centro Médico Nacional Siglo-XXI, Instituto Mexicano del Seguro Social, Mexico City 06720, Mexico

Received November 1, 2018; Accepted June 5, 2019

DOI: $10.3892 / \mathrm{mmr} .2019 .10444$

\begin{abstract}
Recent studies demonstrated that the expression of coxsackievirus and adenovirus receptor (CAR) is implicated in the pathophysiology of myocarditis. The aim of the present study was to assess the association between active and borderline myocarditis and CAR expression in endomyocardial tissues, and analyze the association between CAR expression and treatment response. An analytic, cross-sectional, retrospective study was performed in 26 patients with myocarditis and 10 control subjects without heart disease. Myocardial biopsies were obtained and CAR transcription was measured by reverse transcription-quantitative polymerase chain reaction analysis. The association between CAR mRNA levels and the response to immunosuppressive or conventional therapy (treatment responders, $n=17$; non-responders, $n=9$ )
\end{abstract}

Correspondence to: Dr María G. Cárdenas-Mondragón, Unidad de Investigación Médica en Enfermedades Infecciosas y Parasitarias, UMAE Hospital de Pediatría 'Dr. Silvestre Frenk Freund', Centro Médico Nacional Siglo-XXI, Instituto Mexicano del Seguro Social, Av. Cuauhtémoc 330, Cuauhtémoc, Col. Doctores, Mexico City 06720, Mexico

E-mail: carlupita@yahoo.com.mx

${ }^{*}$ Contributed equally

Key words: coxsackie virus and adenovirus receptor expression, myocarditis, myocardial inflammation or with the type of histological myocarditis (active myocarditis, $n=16$; borderline myocarditis, $n=10$ ) was analyzed. CAR transcription levels were significantly lower $(\mathrm{P}=0.012)$ in patients with myocarditis compared with controls, and a significant decrease was observed $(\mathrm{P}=0.023)$ in CAR mRNA levels among patients with borderline myocarditis compared with the no myocarditis group. Patients responding to therapy exhibited higher CAR mRNA levels $(\mathrm{P}=0.036)$ compared with patients not responding to treatment, as evaluated based on clinical and echocardiographic criteria (immunosuppressive therapy, $n=8$; conventional therapy, $n=1$ ). Myocarditis in non-responders was associated with fewer clinical manifestations and lower CAR mRNA levels. A significant difference was only found regarding the use of oral steroids in patients with active myocarditis who responded to treatment $(\mathrm{P}=0.02)$, with no difference in borderline myocarditis. In conclusion, the transcriptional level of CAR is low in the endomyocardial tissue of patients with myocarditis, and it is lower in borderline myocarditis and in non-responder patients. These findings may enable early identification of patients who may benefit from treatment and timely determination of prognosis.

\section{Introduction}

Myocarditis is an inflammatory disease of the myocardium with a wide clinical spectrum, ranging from asymptomatic to fulminant heart failure (1-3). Myocarditis is underdiagnosed, with an estimated incidence of $0.46-0.72$ per 100,000 and a prevalence to be approximately 22 per 100,000 population annually (4). Autoimmunity and recent infection are risk factors for the development of myocarditis. The main 
etiological agents are viruses, with, the most commonly identified including adenovirus, enterovirus (including coxsackie virus), parvovirus B-19 and human herpesvirus (5). They mainly affect younger patients (20-51 years), $21 \%$ of whom develop dilated cardiomyopathy (DCM), which is associated with a deteriorating quality of life and physical inability to work (6).

Coxsackievirus and adenovirus receptor (CAR) is a transmembrane 46-kDa protein of the Ig superfamily, located in the complex binding between endothelial and epithelial cells $(7,8)$. It is a multifunctional molecule that interacts with proteins involved in cellular communication, adhesion (adherent junctions), binding to the cytoskeleton, regulation and signal transduction, and it has recently been implicated in cardiac remodeling and atrioventricular electrical conduction (7-9). CAR is a common receptor for coxsackievirus and adenovirus, allowing viral binding and endocytosis (10). High CAR mRNA levels have been detected during the late embryonal and early postnatal period (11). CAR transcription is very low in the normal heart, but was found to be overexpressed in patients with DCM and ischemic heart disease; there were no differences regarding age, sex, or CAR mutations between the study groups (12-14).

Regarding the performance of CAR in the presence of myocarditis, most information is derived from animal studies $(13,15-17)$. To the best of our knowledge, there are no studies on the expression of CAR in patients with active myocarditis, and only a few cases have been included in the final sample of protocols with DCM (12-14,18). It remains elusive which proteins are implicated in human myocarditis. In animal models of myocarditis, a difference in the expression of CAR has been documented, considering the time of evolution of the disease. Ito et al (15), reported that CAR expression in rat hearts was low or undetectable prior to disease onset, became evident during the active phase of myocarditis, and decreased in the chronic phase. Similarly, the expression of CAR was preceded by several days of massive inflammatory cell infiltration, and was induced by inflammatory mediators such as interferon $\gamma$, tumor necrosis factor $\alpha$, interleukin $1 \beta$ and nitric oxide synthase (19). Subsequently, CAR induced stress-activated mitogen-activated protein kinase (MAPK) signaling, which may contribute to the development of cardiac inflammation unrelated to the viral infection per se. Consequently, the expression of CAR may not only be associated with myocardial damage in acute myocarditis; due to its role as a cell adhesion molecule $(7,20,21)$, it may also be associated with the phase of healing or regeneration of the damaged myocardium. It is possible that MAPK and NOD2 mediate CAR expression in viral myocarditis $(22,23)$.

The treatment of myocarditis varies, depending on the stage and severity of the patient's clinical profile. Immunosuppressive treatment (usually steroids and azathioprine) has long been used in myocarditis, with varying indications, often based on evidence of myocarditis with inflammatory cell infiltration and inflammatory response. In our hospital, clinical criteria of high probability include de novo arrhythmia, heart failure in a previously healthy patient, severe infectious conditions manifesting prior to the onset of symptoms, low ejection fraction of unknown etiology, and age $<45$ years, as well as the actual presence of histological evidence of myocarditis. Those patients may receive immunosuppressive treatment and are classified as responders or non-responders, based on their response to such treatment.

The aim of the present study was to assess CAR mRNA levels in myocardial biopsies from patients with myocarditis, in order to determine how these may contribute to the clinical evolution of myocarditis.

\section{Materials and methods}

Study design and ethics statement. In this analytical cross-sectional study, CAR mRNA levels were determined by examination of endomyocardial biopsy specimens obtained from patients with myocarditis (17 responders and 9 non-responders to immunosuppressive or conventional therapy; 16 with active and 10 with borderline histological myocarditis) $(2,24)$, and subjects without myocarditis. The present study was approved by the National Research Scientific and Ethics Committee of Instituto Mexicano del Seguro Social (IMSS). The study protocol conformed to the principles outlined in the Declaration of Helsinki. All the participants were informed on the nature of the study and provided written consent.

Study population. The study included 36 patients (aged $>18$ years) between January 2009 and May 2015. A total of 26 patients were diagnosed with myocarditis by endomyocardial biopsy (histopathological, immunological and immunohistochemical criteria). A total of 10 subjects who underwent endomyocardial biopsy (EMB) for on suspicion of myocarditis and in whom the histopathological findings were not compatible with myocarditis, or myocardial samples obtained by necropsies in which the histopathological findings were considered as normal, comprised the non-cardiac disease (NM group, without myocarditis also showed no other signs of cardiovascular disease; the characteristics of this group will be described in Results section). The samples obtained from autopsies performed immediately after death and that were formalin-fixed and embedded in paraffin for their preservation. The patients were admitted to the Heart Failure Clinic, Cardiology Hospital of the Centro Medico Nacional Siglo XXI (CMN-Siglo XXI), IMSS, in Mexico City. The treatment method was at the discretion of the treating physician.

Sample/data collection. The endomyocardial samples were collected from the Department of Pathology of the Cardiology Hospital CMN-Siglo XXI; IMSS. For all cases, formalin-fixed and paraffin-embedded samples were available. An expert pathologist analyzed all the samples to confirm the diagnosis.

Socio-demographic data and clinical information were recorded at the time of inclusion. The collected information included age, sex, clinical presentation (medical history, symptoms, signs and non-invasive assessment) and histological diagnosis. Other parameters included left ventricular ejection fraction (LVEF), troponins, functional class, and response or lack thereof to immunosuppressive therapy (evaluated based on clinical and echocardiographic criteria) (24).

Histopathological examination. EMB was used for histopathological diagnosis by optical and electron microscopy. Sections 
Table I. General characteristic of the study population according to diagnosis with myocarditis by histopathological examination and clinical criteria.

\begin{tabular}{lccc}
\hline Variable & Active myocarditis & Borderline myocarditis & P-value \\
\hline $\mathrm{n}(\%)$ & $16(61.5)$ & $10(38.5)$ & $0.792^{\mathrm{a}}$ \\
Age, years (Mean $\pm \mathrm{SD})$ & $35.4 \pm 13.9$ & $36.9 \pm 13.7$ & $0.088^{\mathrm{b}}$ \\
Sex, male/female ratio & $8 / 8=1.0$ & $9 / 1=9$ & \\
Cardiovascular risk factors & & & $0.385^{\mathrm{b}}$ \\
Diabetes mellitus, $\mathrm{n}(\%)$ & $0(0)$ & $1(10)$ & $0.046^{\mathrm{b}, \mathrm{d}}$ \\
Systemic hypertension, $\mathrm{n}(\%)$ & $0(0)$ & $3(30)$ & $0.055^{\mathrm{b}}$ \\
Dyslipidemia, $\mathrm{n}(\%)$ & $1(6.3)$ & $4(40)$ & $0.689^{\mathrm{c}}$ \\
Smoking, $\mathrm{n}(\%)$ & $6(37.5)$ & $5(50)$ & $0.562^{\mathrm{a}}$ \\
Body mass index $\left(\mathrm{kg} / \mathrm{m}^{2}\right)$, median (range) & $26.7(18.8-39.4)$ & $27.7(23.4-33.96)$ & \\
Background of recent infection & & & $0.248^{\mathrm{b}}$ \\
Airways, $\mathrm{n}(\%)$ & $7(43.8)$ & $0(0)$ & $0.508^{\mathrm{b}}$ \\
Gastrointestinal, $\mathrm{n}(\%)$ & $2(12.5)$ & $(70)$ & \\
\hline
\end{tabular}

${ }^{\mathrm{a}}$ Mann-Whitney U test. ${ }^{\mathrm{b}}$ Fisher exact test. ${ }^{\text {Pearson }}$ Chi square. ${ }^{\mathrm{d}} \mathrm{P}<0.05$.

from EMB were stained with hematoxylin and eosin $(\mathrm{H} \& \mathrm{E})$. The gold standard for diagnosis was EMB in conjunction with determination of immunohistochemical markers, according to the 1995 World Health Organization/International Society and Federation of Cardiology classification of cardiomyopathies (2). The histological level of inflammation in each lesion was graded according to the Dallas criteria (25). The Dallas criteria classify myocarditis as follows: i) Active myocarditis, defined as an inflammatory infiltration of the myocardium with necrosis and/or degeneration of adjacent myocytes, not typical of ischemic damage associated with coronary artery disease. The infiltrating cells are usually mononuclear, but may include neutrophils and occasional eosinophils; and ii) borderline myocarditis, which is a term used when the inflammatory infiltrate is small, or myocyte damage is not apparent.

All diagnoses and classifications were reviewed by hospital expert pathologists who were blinded to the patients' clinical data. According to the above mentioned criteria, 16 patients were diagnosed with active myocarditis and 10 with borderline myocarditis.

Deparaffinization and digestion of tissues. For RNA extraction, the samples were obtained by deparaffinization of formalin-fixed paraffin-embedded samples. For each paraffin-embedded sample, 5 sections of 10 microns were obtained. Between each microtome cut, the cutting blade was wiped with ethanol to remove ribonuclease (RNase). Excess paraffin around the section was removed with a razor knife. The first two sections were removed due to the risk of the presence of RNases. The sections were immediately placed in a microtube and $1 \mathrm{ml}$ xylene was added, followed by incubating twice for $3 \mathrm{~min}$ at $42^{\circ} \mathrm{C}$ with stirring, centrifuging at $18,407 \mathrm{~g}$ between each incubation for $5 \mathrm{~min}$ and removing the supernatant. The tissue was washed with $1 \mathrm{ml}$ of absolute ethanol three times for $3 \mathrm{~min}$ each time at room temperature with stirring, with centrifugation at maximum speed $21,130 \mathrm{~g}$ each time. The residual ethanol was allowed to evaporate until the tissue was completely dry. A total of $350 \mu \mathrm{l}$ tissue digestion buffer [proteinase $\mathrm{K}$ treatment with $500 \mathrm{mg} / \mathrm{ml} \mathrm{mM}$ Tris $\mathrm{HCl}$ (pH 8), $10 \mathrm{mM}$ EDTA, 1\% SDS] was added per heart sample and incubated at $42^{\circ} \mathrm{C}$ for $\sim 24 \mathrm{~h}$ with stirring, until the heart tissue had been lysed and digested (26).

Total RNA extraction and RNA purification. Total RNA was extracted from degraded heart tissues by adaptation of the hot phenol method (27). Briefly, after the lysed sample was obtained, $500 \mu \mathrm{l}$ of phenol acid preheated to $65^{\circ} \mathrm{C}$ was added, vortexed and incubated at $65^{\circ} \mathrm{C}$ for $5 \mathrm{~min}$. The samples were centrifuged at $18,407 \mathrm{~g}$ for $5 \mathrm{~min}$ at room temperature. The aqueous phase was transferred to a clean microtube with $1 \mathrm{ml}$ of cold absolute ethanol and incubated at $-70^{\circ} \mathrm{C}$ for at least $30 \mathrm{~min}$. The RNA was pelleted by centrifugation at $18,407 \mathrm{~g}$ for $10 \mathrm{~min}$ at $4^{\circ} \mathrm{C}$. Pellets were washed by adding $1 \mathrm{ml} \mathrm{70 \%} \mathrm{cold} \mathrm{ethanol} \mathrm{and} \mathrm{centrifuged} \mathrm{at} 13,523 \mathrm{~g}$ for $2 \mathrm{~min}$ at $4^{\circ} \mathrm{C}$ to precipitation. The pellets were dried in the Centrifugal Vacuum Concentrator 5301 (Eppendorf). The pellets were resuspended in $30 \mu \mathrm{l}$ ultrapure DEPC-treated water (Invitrogen; Thermo Fisher Scientific, Inc.). DNA was removed with the Turbo DNA-Free kit (AM1907; Ambion; Thermo Fisher Scientific, Inc.). The amount and quality of RNA were evaluated by measuring the optical density (OD) at 260/280 ratios using a Nanodrop spectrophotometer (ND-100, Nanodrop, Thermo Fisher Scientific, Inc.). The RNA quality was assessed using a bleach gel with $2 \%$ agarose, as previously described (28).

$C A R$ expression by reverse transcription quantitative $P C R$ $(R T-q P C R)$ analysis. The quantification of CAR transcription from the samples was performed by RT-qPCR using LightCycler $^{\circledR} 480$ SYBR Green I Master (4707516001; Roche). cDNA was synthesized with $100 \mathrm{ng}$ of each RNA sample, $0.22 \mu \mathrm{g} / \mu \mathrm{l}$ random hexamer primers and $2 \mathrm{U} / \mu \mathrm{l}$ Reverse transcriptase of Moloney Murine Leukemia Virus (M-MuLV-RT; Thermo Fisher Scientific, Inc.). The cDNA generated was used 
for qPCR using a LightCycler 480 thermocycler (Roche) and the following primer pairs: For the human CAR gene, 5'-GCC CACTTCATGGTTAGCAG-3' and 5'-TACGGCTCTTTG GAGGTGGC-3' (13). For the housekeeping $\beta$-globin gene, 5'-ACACAACTGTGTTCACTAGC-3' and 5'-TGGTCTCCT TAAACCTGTCTTG-3'; and for the $\beta$-actin gene, 5 '-TCG TGCGTGACATTAAGGAG and 5'-TTGCCAATGGTGATG ACCTG 3'. The PCR reactions were carried out in a total volume of $10 \mu 1$, containing $1.5 \mu 1$ molecular grade sterile water included in the commercial kit, $0.5 \mu \mathrm{l}$ of each specific primer pair corresponding to a concentration of $20 \mu \mathrm{M}, 2.5 \mu \mathrm{l}$ cDNA to the appropriate dilution, and $5.0 \mu \mathrm{l}$ of the mixture of 2X Master SYBR Green I, which contains FastStart Taq DNA polymerase, reaction buffer, dNTP mixture, fluorochrome SYBR Green I and $\mathrm{MgCl}_{2}$. Each sample was assessed in triplicate. The qPCR analysis was performed using the following optimized assay conditions: Denaturation at $95^{\circ} \mathrm{C}$ for $10 \mathrm{~min}$, followed by amplification repeated for 45 cycles at $95^{\circ} \mathrm{C}$ for $10 \mathrm{sec}$, quantification at $58^{\circ} \mathrm{C}$ for $20 \mathrm{sec}$ and extension at $72^{\circ} \mathrm{C}$ for $30 \mathrm{sec}$ with single-measurement fluorescence. A melting curve analysis was run at $95^{\circ} \mathrm{C}$ for $10 \mathrm{sec}, 65^{\circ} \mathrm{C}$ for $1 \mathrm{~min}$ with continuous measurement of fluorescence at $97^{\circ} \mathrm{C}$, and finally a cooling step at $40^{\circ} \mathrm{C}$ for $10 \mathrm{sec}$. Analysis of the melting curve after each run was performed to confirm the specificity of the primers. The mRNA levels of CAR were calculated from the relative quantification of CAR and the level of reference genes determined for each sample (29). For mRNA level quantification, the $\Delta \Delta \mathrm{Cq}$ method was used (30). Genes coding for $\beta$-globin and/or $\beta$-actin were used as reference for normalization.

Statistical analysis. Differences among $\geq 3$ groups were compared by one-way analysis of variance followed by post-hoc Scheffe's test, or by the Kruskal-Wallis test followed by Mann-Whitney U test for non-normally distributed variables. For comparison of CAR expression, the latter tests were used, as they do not assume a normal distribution. A two-tailed $\mathrm{P}<0.05$ was considered to indicate statistically significant differences. Bivariate analysis was used for categorical variables with Pearson Chi-squared or Fisher's exact test for small samples.

\section{Results}

Subjects. A total of 36 patients were included in the cross-sectional study, among whom 10 patients did not meet the criteria for myocarditis and non-cardiac disease (NCD) and were considered as the control group without myocarditis (no myocarditis; NM group). The NM group mainly comprised samples obtained from autopsies preserved over a period of 5 years; the median patients age was $38.3 \pm 13$. 8 years, the sex ratio was 1:1, and the main diagnosis was hemorrhagic stroke (50\%) and thrombophilia. Cases with a history of treatment with immunosuppressants or immunomodulatory drugs, history of ischemic heart disease, systemic viral infections, autoimmune diseases, congenital or acquired immunodeficiencies and cancer were excluded. Also, histologically, the myocardium was considered normal, without any evidence of ischemia, myocarditis or other cardiac disease that would interfere with our analysis. The remaining patients $(n=26)$ were

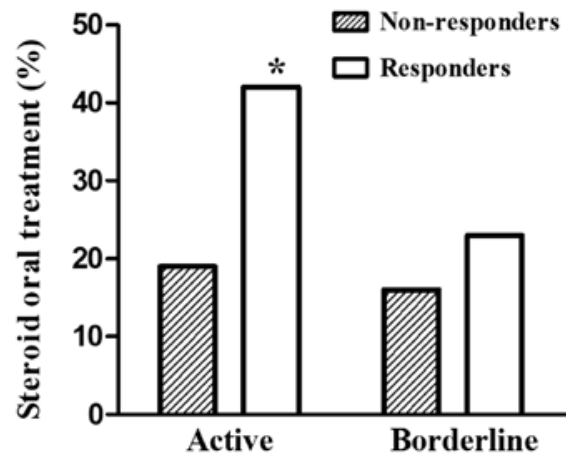

Figure 1. Distribution in frequency of treatment with oral steroids in non-responders and responders, according to kind of myocarditis. It should be noted that among subjects with active myocarditis, these was a greater frequency in oral steroid treatment. Regarding analysis of the treatment used with relation to the kind of myocarditis, significant difference was only found for the use of oral steroids in subjects with active myocarditis, being higher in the responders $(\mathrm{P}=0.02$, Pearson Chi square).

diagnosed with myocarditis by histopathological and clinical criteria; 16 patients had active myocarditis and 10 had borderline myocarditis according to the Dallas criteria (Table I).

Active and borderline myocarditis. The group of patients with active myocarditis comprised 8 men and 8 women, with a mean age of $35.4 \pm 13.9$ years, while the borderline myocarditis group included 9 men and 1 woman, with a mean age of $36.9 \pm 13.7$ years. No difference in age was observed between the NM group and patients with active myocarditis or those with borderline myocarditis. The main characteristics at the time of diagnosis according to histopathological examination (active and borderline myocarditis) are summarized in Table II.

No differences in clinical presentation (dyspnea, chest pain, palpitations, syncope), functional class, findings on physical examination, laboratory and electrocardiography findings and echocardiography findings were observed between the two groups. Significant differences between active and borderline myocarditis were only found in terms of cardiac frequency $(\mathrm{P}=0.015)$, LVEF $(\mathrm{P}=0.005)$ and tricuspid annular plane systolic excursion (TAPSE) ( $\mathrm{P}=0.01$; Table II).

A total of 17 (65.4\%) of the 26 patients histologically diagnosed with myocarditis by endomyocardial biopsy exhibited a satisfactory response to therapy (Table III), confirmed by echocardiographic variables before and after medical treatment, and according to the definition of such groups by Frustaci et al (24). A total of 11 (64.7\%) of the responder patients had active myocarditis and $6(35.3 \%)$ patients had borderline myocarditis. Regarding analysis of the treatment used with relation to the type of myocarditis, the frequency was higher ( $\mathrm{P}=0.02$; Pearson Chi square) for the use of oral steroids in responders compared with non-responders in subjects with active myocarditis; there was no significant difference in the use of steroids between responders and non-responders in borderline myocarditis (Fig. 1). Significant differences in cardiac frequency $(\mathrm{P}=0.01)$, tachyarrhythmia $(\mathrm{P}=0.046)$, LVEF $(\mathrm{P}=0.004)$ and TAPSE $(\mathrm{P}=0.016)$ were found at the time of diagnosis between responders and non-responders (Table IV). The responders exhibited a higher 
Table II. Clinical characteristics at the time of diagnosis according to histopathological examination.

\begin{tabular}{|c|c|c|c|}
\hline Variable & Active $n=16$ & Borderline $n=10$ & P-value \\
\hline \multicolumn{4}{|l|}{ Clinical symptoms } \\
\hline Dyspnea, n (\%) & $8(50)$ & $7(70)$ & $0.428^{\mathrm{b}}$ \\
\hline Chest pain, $\mathrm{n}(\%)$ & $10(62.5)$ & $6(60)$ & $0.609^{\mathrm{b}}$ \\
\hline Palpitations, n (\%) & $6(37.5)$ & $1(10)$ & $0.190^{\mathrm{b}}$ \\
\hline Syncope, n (\%) & $5(31.3)$ & $2(20)$ & $0.668^{\mathrm{b}}$ \\
\hline \multicolumn{4}{|l|}{ Functional class (NYHA) } \\
\hline CF-I-II, n (\%) & $13(81.3)$ & $9(90)$ & $0.496^{\mathrm{b}}$ \\
\hline CF III-IV, n (\%) & $3(18.8)$ & $1(10)$ & $0.496^{\mathrm{b}}$ \\
\hline \multicolumn{4}{|l|}{ Physical findings upon exploration } \\
\hline Cardiac frequency (bpm) median (range) & $90(30-130)$ & $67(40-88)$ & $0.015^{\mathrm{a}, \mathrm{d}}$ \\
\hline Hypotension, n (\%) & 0 & $2(20)$ & $0.138^{\mathrm{b}}$ \\
\hline Rales, n (\%) & $4(25)$ & $3(30)$ & $0.562^{\mathrm{b}}$ \\
\hline \multicolumn{4}{|l|}{ Laboratory findings } \\
\hline Maximum troponin, median (range) (ng/ml) & $2.4(0.01-30)$ & $0.05(0.1-13.3)$ & $0.238^{\mathrm{a}}$ \\
\hline Total CPK maximum, median (range) (U/l) & $595(56-2,444)$ & $185.5(63-1,690)$ & $0.350^{\mathrm{a}}$ \\
\hline Total CPK-MB maximum, median (range) (Ul) & $46.5(1-301)$ & $22(15.4-138)$ & $0.433^{\mathrm{a}}$ \\
\hline \multicolumn{4}{|l|}{ Electrocardiograph findings } \\
\hline Prolonged QRS (>120 m sec), n (\%) & $6(37.5)$ & $4(40)$ & $0.609^{\mathrm{b}}$ \\
\hline AV blockage, n (\%) & $4(25)$ & $2(20)$ & $0.580^{\mathrm{b}}$ \\
\hline Tachyarrhythmia, n (\%) & $8(50)$ & $2(20)$ & $0.218^{\mathrm{b}}$ \\
\hline \multicolumn{4}{|l|}{ Echocardiograph findings } \\
\hline LVEF (\%) median (range) & $35(13-57)$ & $60(31-70)$ & $0.005^{\mathrm{a}, \mathrm{e}}$ \\
\hline LVEF $<45 \%, \mathrm{n}(\%)$ & $8(50)$ & $5(50)$ & $0.656^{\mathrm{b}}$ \\
\hline Right ventricular dysfunction, n (\%) & $4(25)$ & $3(33)$ & $0.673^{\mathrm{b}}$ \\
\hline Ventricular dysfunction, n (\%) & $9(56)$ & $5(50)$ & $0.756^{\mathrm{c}}$ \\
\hline PASP (mmHg) median (range) & $30.5(17-46)$ & $37.5(25-50)$ & $0.053^{\mathrm{a}}$ \\
\hline TAPSE (mm) median (range) & $18(11-27)$ & $21,5(19-26)$ & $0.017^{\mathrm{a}, \mathrm{d}}$ \\
\hline
\end{tabular}

${ }^{\mathrm{a}}$ Mann-Whitney U test. ${ }^{\mathrm{b}}$ Fisher exact test. ${ }^{\mathrm{c}} \mathrm{Pearson}$ Chi squared. ${ }^{\mathrm{d}} \mathrm{P}<0.05,{ }^{\mathrm{e}} \mathrm{P}<0.01$. NYHA, New York Heart Association; CF, Functional class; bpm, beats per minute; CPK, Creatine phosphokinase; $\mathrm{MB}$, isoform muscle/brain; AV, atrioventricular; LVEF, Left ventricular ejection fraction; PSAP, Pulmonary artery systolic pressure; TAPSE, Tricuspid annular plane systolic excursion.

$(\mathrm{P}=0.038)$ level of ventricular dysfunction (LVEF $<45 \%$ and/or right ventricular dysfunction).

The median follow-up time was 12 months (range, 2-72 months), which was mainly determined by the time the diagnosis was made. The responder patients had significantly lower initial LVEF and initial pulmonary artery systolic pressure $(\mathrm{P}=0.017$; Table $\mathrm{V})$, whereas the non-responders exhibited deterioration of the initial LVEF (median decrease of $10 \%$; range, $1-20 \%$ ).

CAR expression in myocarditis. The expression levels of CAR were significantly lower in patients with myocarditis $(\mathrm{P}=0.012)$ compared with those in the NM group (Fig. 2A). CAR expression was significantly lower in patients with borderline myocarditis $[\mathrm{P}=0.023$; median, 3.5 (range, 0.70-435.5)] and active myocarditis $[\mathrm{P}=0.029$; median, 12.3 (range, 0.26-71.3); Mann-Whitney U test)] compared with that in the NM control group [median, 30.7 (range, 10.8-94.6)] (Fig. 2B).
The CAR mRNA levels according to treatment response are shown in Fig. 2C [improvement assessed by clinical and echocardiographic criteria, as defined by Frustaci et al (24)]. Responder patients exhibited higher transcription of CAR ( $\mathrm{P}=0.036$, Mann-Whitney U test) [median, 15.9 (range, 0.14-435)] compared with non-responders [median, 1.5 (range, 0.7-23.8)]. The CAR mRNA levels were significantly lower in non-responder patients with myocarditis $(\mathrm{P}=0.001)$ compared with those in the NM control group. This difference was estimated by relative expression of the housekeeping genes $\beta$-actin and $\beta$-globin (data not shown).

\section{Discussion}

The present study involved NM patients and patients with myocarditis. In line with the findings reported by Hufnagel et al (31), we observed that the main clinical manifestations in symptomatic patients included chest pain, dyspnea, palpitations and syncope, in that order of frequency. In the 
Table III. General description of the study population according the treatment response.

\begin{tabular}{|c|c|c|c|}
\hline Variable & Responders & Non-responders & P-value ${ }^{a}$ \\
\hline $\mathrm{n}(\%)$ & $17(65.4)$ & $9(34.6)$ & \\
\hline Age, years $($ Mean \pm SD) & $36.4 \pm 14.3$ & $35.2 \pm 13.2$ & $0.850^{\mathrm{a}}$ \\
\hline Sex, male/female ratio & $12 / 5=2.4$ & $5 / 4=1.25$ & $0.528^{\mathrm{b}}$ \\
\hline \multicolumn{4}{|l|}{ Myocarditis } \\
\hline Active, n (\%) & $11(64.7)$ & $5(55.6)$ & $0.692^{\mathrm{b}}$ \\
\hline Borderline, n (\%) & $6(35.3)$ & $4(44.4)$ & $0.692^{\mathrm{b}}$ \\
\hline \multicolumn{4}{|l|}{ Treatment } \\
\hline Immunosuppressive, $\mathrm{n}(\%)$ & $14(82.4)$ & $8(88.9)$ & $0.569^{\mathrm{b}}$ \\
\hline Conventional, n (\%) & $3(17.6)$ & $1(11.1)$ & $0.569^{\mathrm{b}}$ \\
\hline \multicolumn{4}{|l|}{ Cardiovascular risk factors } \\
\hline Diabetes mellitus, n (\%) & $1(5.9)$ & $0(0)$ & $0.654^{\mathrm{b}}$ \\
\hline Systemic hypertension, $\mathrm{n}(\%)$ & $2(11.8)$ & $1(11.1)$ & $0.732^{\mathrm{b}}$ \\
\hline Dyslipidemia, n (\%) & $5(29.4)$ & $0(0)$ & $0.129^{\mathrm{b}}$ \\
\hline Smoking, n (\%) & $7(41.2)$ & $4(44.4)$ & $0.598^{\mathrm{b}}$ \\
\hline Body mass index $\left(\mathrm{kg} / \mathrm{m}^{2}\right)$, median (range) & $26.5(18.8-39.4)$ & $27.7(22.4-29)$ & $0.957^{\mathrm{a}}$ \\
\hline \multicolumn{4}{|l|}{ Antecedent of recent infection } \\
\hline Airways, n (\%) & $10(58.8)$ & $4(44.4)$ & $0.683^{\mathrm{b}}$ \\
\hline Gastrointestinal, n (\%) & $2(11.8)$ & $0(0)$ & $0.529^{\mathrm{b}}$ \\
\hline
\end{tabular}

${ }^{\mathrm{a}}$ Mann-Whitney U test. ${ }^{\mathrm{b}}$ Fisher exact test.

A
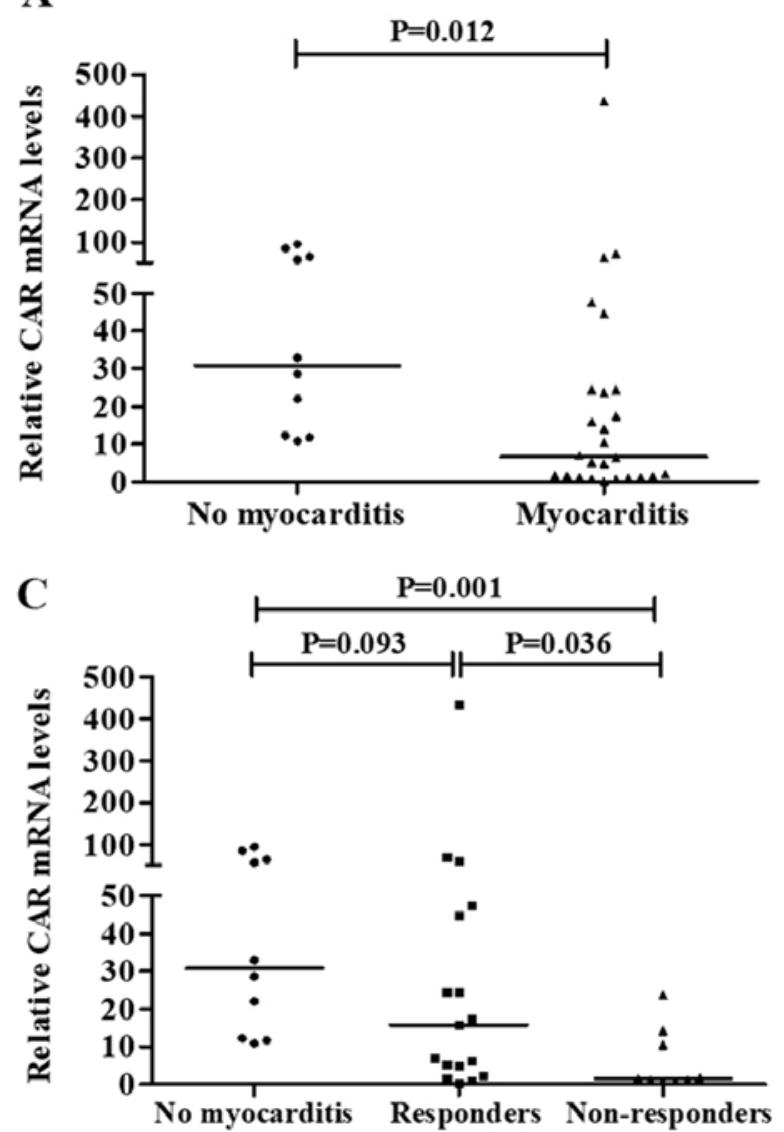

B

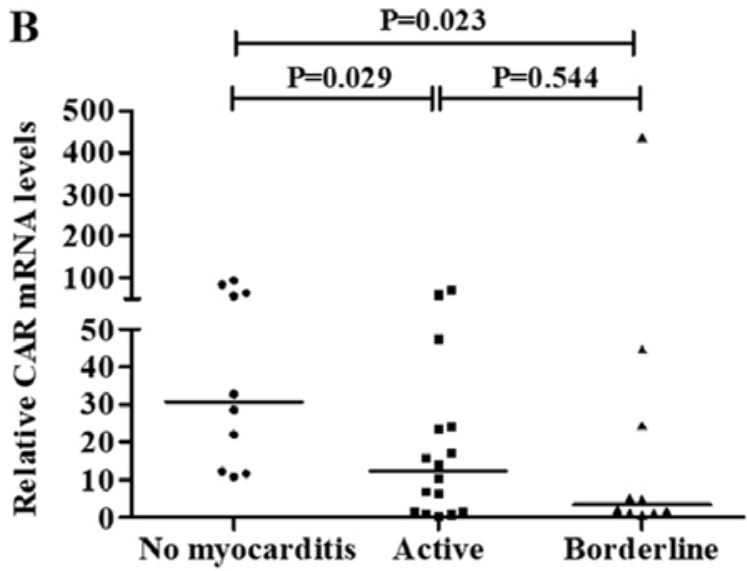

Figure 2. Transcription of CAR, using $\beta$-actin as a reference gene for normalization. (A) CAR mRNA levels in patients with myocarditis ( $\mathrm{n}=26$ ) vs. no myocarditis. (B) According to the different types of myocarditis; borderline myocarditis $(n=10)$ and active myocarditis ( $n=16)$ vs. no myocarditis, and in relation to treatment response; $(C)$ treatment responder patients $(n=17)$ and non-responders to therapy $(n=9)$ vs. no myocarditis. CAR, coxsackievirus and adenovirus receptor. 
Table IV. Clinical characteristics at the time of diagnosis according the treatment response.

\begin{tabular}{|c|c|c|c|}
\hline Variable & Responders $\mathrm{n}=17$ & Non-responders $n=9$ & P-value \\
\hline \multicolumn{4}{|l|}{ Clinical symptoms } \\
\hline Dyspnea, n (\%) & $12(70.6)$ & $3(33.3)$ & $0.103^{\mathrm{b}}$ \\
\hline Chest pain, n (\%) & $12(70.6)$ & $4(44.4)$ & $0.234^{\mathrm{b}}$ \\
\hline Palpitations, n (\%) & $3(17.6)$ & $4(44.4)$ & $0.188^{\mathrm{b}}$ \\
\hline Syncope, n (\%) & $3(17.6)$ & $4(44.4)$ & $0.188^{\mathrm{b}}$ \\
\hline \multicolumn{4}{|l|}{ Functional class (NYHA) } \\
\hline CF-I-II, n (\%) & $15(88.2)$ & $7(77.8)$ & $0.591^{\mathrm{b}}$ \\
\hline CF III-IV, n (\%) & $2(11.8)$ & $2(22.2)$ & $0.591^{\mathrm{b}}$ \\
\hline \multicolumn{4}{|l|}{ Physical findings upon exploration } \\
\hline Cardiac frequency (bpm) median (range) & $90(30-130)$ & $67(40-88)$ & $0.010^{\mathrm{a}, \mathrm{d}}$ \\
\hline Hypotension, n (\%) & $2(11.8)$ & 0 & $0.529^{\mathrm{b}}$ \\
\hline Rales, n (\%) & $6(35.3)$ & $1(11.1)$ & $0.357^{\mathrm{b}}$ \\
\hline \multicolumn{4}{|l|}{ Laboratory } \\
\hline Maximum troponin, median (range) (ng/ml) & $7.9(0.01-30)$ & $3.3(0.01-13.3)$ & $0.26^{\mathrm{a}}$ \\
\hline Total CPK maximum, median (range) (U/l) & $806(56-2,444)$ & $438(63-1,690)$ & $0.38^{\mathrm{a}}$ \\
\hline Total CPK-MB maximum, median (range) (U/1) & $72(1-301)$ & $43(15-138)$ & $0.445^{\mathrm{a}}$ \\
\hline \multicolumn{4}{|l|}{ Electrocardiograph findings } \\
\hline Prolonged QRS (>120 msec), n (\%) & $6(35.3)$ & $4(44.4)$ & $0.692^{\mathrm{b}}$ \\
\hline AV blockage, n (\%) & $4(23.5)$ & $2(22.2)$ & $0.580^{\mathrm{b}}$ \\
\hline Tachyarrhythmia, n (\%) & $4(23.5)$ & $6(66.7)$ & $0.046^{\mathrm{b}, \mathrm{c}}$ \\
\hline \multicolumn{4}{|l|}{ Echocardiograph findings } \\
\hline LVEF (\%) median (range) & $35(13-57)$ & $60(31-70)$ & $0.004^{\mathrm{a}, \mathrm{d}}$ \\
\hline $\mathrm{LVEF}<45 \%, \mathrm{n}(\%)$ & $11(64.7)$ & $2(22.2)$ & $0.097^{\mathrm{b}}$ \\
\hline Right ventricular dysfunction, n (\%) & $7(41.2)$ & 0 & $0.057^{\mathrm{b}}$ \\
\hline Ventricular dysfunction, n (\%) & $12(70.6)$ & $2(22.2)$ & $0.038^{\mathrm{b}, \mathrm{c}}$ \\
\hline PASP $(\mathrm{mmHg})$ median (range) & $34(17-50)$ & $27(25-40)$ & $0.181^{\mathrm{a}}$ \\
\hline TAPSE (mm) median (range) & $18(11-27)$ & $21.5(19-26)$ & $0.016^{\mathrm{a}, \mathrm{c}}$ \\
\hline
\end{tabular}

${ }^{\mathrm{a}}$ Mann-Whitney U test. ${ }^{\mathrm{b}}$ Fisher exact test. ${ }^{\mathrm{c}} \mathrm{P}<0.05$. ${ }^{\mathrm{d}} \mathrm{P}<0.01$. NYHA, New York Heart Association; CF, Functional class; bpm, beats per minute; CPK, Creatine phosphokinase; MB, isoform muscle/brain; AV, atrioventricular; LVEF, Left ventricular ejection fraction; PSAP, Pulmonary artery systolic pressure.

A

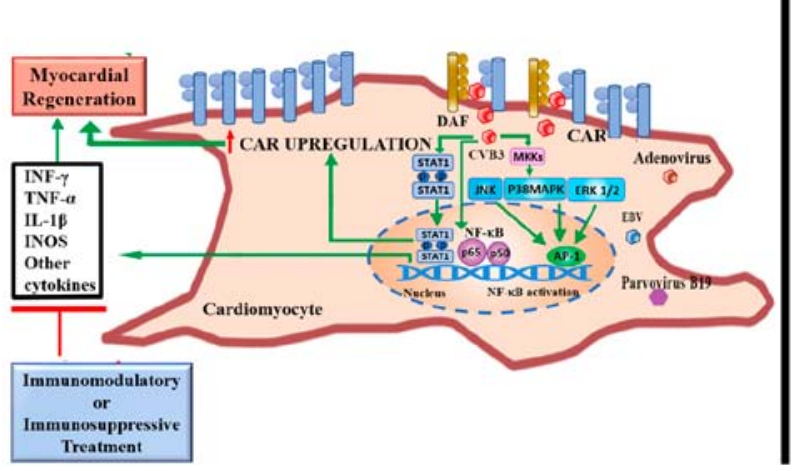

\section{B}

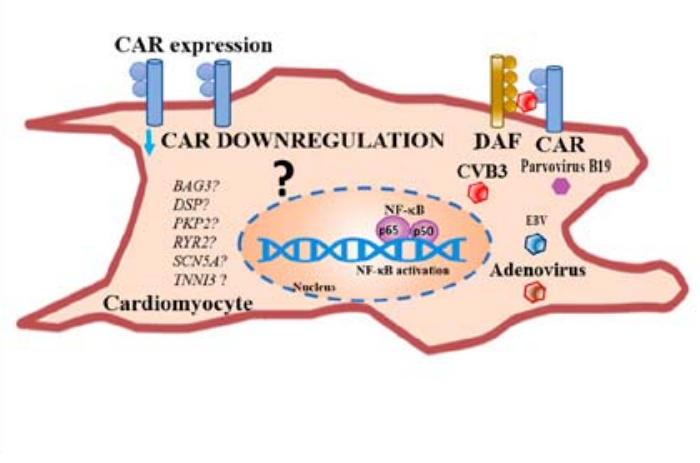

Figure 3. Proposed pathophysiological mechanisms that could explain the presence or absence of response to treatment in myocarditis. (A) Represents the scenario proposed in patients with response to treatment; in these patients there is an up-regulation of CAR mRNA levels, which has been related to the STAT1 signaling pathway, as well as a greater inflammatory response mediated by JNK and p38MAPK with increased synthesis of interferon gamma (INF- $\gamma$ ), tumor necrosis factor $\alpha(\mathrm{TNF}-\alpha)$, interleukin $1 \beta(\mathrm{IL}-1 \beta)$ and nitric oxide synthase (iNOS); thus, CAR induces signals that activate cellular effectors and cytokine responses characteristic of innate or acquired immunity independently of viral infection type. In this sense, the use of immunosuppressants or immunomodulators may be important because it blocks the inflammatory effect of the over-expression of CAR mRNA levels without affecting its cellular adhesion molecule function, which has been associated with the healing phase or regeneration of damaged myocardium. (B) Represents the scenario in patients without response to treatment; in these patients there is a lower transcription of CAR; however, the rest of the pathophysiological pathway is still unknown [modified from Ghigo et al (36)]. 
Table V. Echocardiographic behavior of patients in relation to response to treatment.

\begin{tabular}{|c|c|c|c|}
\hline Variable & Responders & Non-responders & P-value ${ }^{a}$ \\
\hline \multicolumn{4}{|l|}{$\operatorname{LVEF}(\%)$} \\
\hline Initial & $35(13-57)$ & $60(31-70)$ & $0.004^{\mathrm{a}, \mathrm{c}}$ \\
\hline Follow-up & $60(26-75)$ & $42(24-66)$ & $0.155^{\mathrm{a}}$ \\
\hline \multicolumn{4}{|c|}{ Diastolic VI diameter (mm) } \\
\hline Initial & $54(40-72)$ & $48(43-77)$ & $0.646^{\mathrm{a}}$ \\
\hline Follow-up & $48(33-58)$ & $51(41-77)$ & $0.513^{\mathrm{a}}$ \\
\hline \multicolumn{4}{|c|}{ Systolic VI diameter (mm) } \\
\hline Initial & $40(30-61)$ & $32(28-65)$ & $0.145^{\mathrm{a}}$ \\
\hline Follow-up & $32(20-51)$ & $39(20-57)$ & $0.281^{\mathrm{a}}$ \\
\hline \multicolumn{4}{|c|}{ PASP (mmHg) } \\
\hline Initial & $34(17-50)$ & $27(25-40)$ & $0.168^{\mathrm{a}}$ \\
\hline Follow-up & $29(22-43)$ & $35(25-47)$ & $0.065^{\mathrm{a}}$ \\
\hline \multicolumn{4}{|l|}{ TAPSE (mm) } \\
\hline Initial & $18(11-27)$ & $21(16-26)$ & $0.016^{\mathrm{a}, \mathrm{b}}$ \\
\hline Follow-up & $21(17-27)$ & $20(18-24)$ & $0.669^{\mathrm{a}}$ \\
\hline
\end{tabular}

Data are presented as median (range). ${ }^{\mathrm{a}}$ Mann-Whitney $\mathrm{U} .{ }^{\mathrm{b}} \mathrm{P}<0.05 .{ }^{\mathrm{c}} \mathrm{P}<0.01 . \mathrm{LVEF}$, Left ventricular ejection fraction; PSAP, Pulmonary artery systolic pressure; TAPSE, Tricuspid annular plane systolic excursion.

literature, a history of recent infection is reported as one of the main predisposing factors for the development of myocarditis. The presence of this factor (mainly airway infections) was documented in over half of the population of the present study.

Myocarditis can be classified considering several characteristics, which emphasize, among others, causal agent, histological findings (Dallas criteria) (32), time of evolution and clinicopathological background (33). However, histological classification remains the gold standard for its diagnosis. In the present study, no statistically significant differences were observed between the two groups (active and borderline) in terms of age, cardiovascular risk factors and predisposing factors. Regarding the initial clinical presentation, patients with active myocarditis presented with higher heart rate, as well as lower LVEF and TAPSE, compared with borderline myocarditis, in contrast to the study of Angelini et al (34), who reported a higher incidence of left bundle branch block in patients with borderline myocarditis, as well as higher left ventricular end-diastolic volume and lower ventricular mass/volume ratio. However, despite the clinical differences, the presence of myocardial necrosis is not considered an indicator of unfavorable prognosis, as might be expected; the histological finding of active or borderline myocarditis does not affect the evolution and severity of the disease, or the response to treatment.

In animal models of myocarditis, a differential expression was observed in each of the stages of this pathology according with the evolution time. Ito et al (15) reported that the expression of CAR in rat hearts was low or undetectable prior to disease onset, became evident during the active phase of myocarditis and decreased in the chronic phase. The CAR transcriptional level was found to be lower in patients with myocarditis compared with that in controls, and it was lower in patients with borderline compared with those with active myocarditis. These results are in agreement with Kaur et al (12), who evaluated 9 cases of myocarditis, without finding a statistically significant association between CAR positivity and active myocarditis in any of the groups.

The study of myocarditis in humans is limited by ethical issues, therefore it was necessary to revert to autopsies in order to establish reference points. The use of myocardial tissue from autopsies as control samples for experimental studies in myocarditis has been carried out by several international researchers. Tatrai et al (14), in a period from 2005 to 2008, used 10 controls to assess the expression of CAR mRNA and mutations of the CAR gene, the myocardial tissue was obtained from individuals who died suddenly of accident or suicide. Also, Kaur et al (12) determined the expression of CAR in myocardial tissue, the study was performed on autopsied myocardial tissues preserved over a period of 10 years, formalin-fixed, collected from 26 myocarditis/DCM patients and 20 cases each of NCD and cardiac disease other than DCM were included as control groups (12).

Of note, the focus of the present study was the behavior of CAR considering in terms of response to treatment. To the best of our knowledge, this is the first study to document higher transcription of this molecule in patients with adequate response to treatment, despite the fact that these patients exhibited greater ventricular dysfunction at the time of diagnosis.

The treatment of myocarditis remains debated upon, since the use of immunosuppression and/or immunomodulation is not universally accepted, and there is lack of evidence-based guidelines in favor of such therapeutic options. However, there is currently no method that predicts whether a patient 
will respond to that treatment. The present study provided molecular evidence of an increased level of CAR transcription in patients responding to therapy (immunosuppressive or conventional) compared with non-responders. In addition, response to treatment among patients with active myocarditis was associated with a greater frequency of oral steroid use compared with non-responders. Moreover, the responder patients had a higher incidence of ventricular dysfunction and other abnormal clinical variables. These results support the hypothesis of Ito et al (15) and Noutsias et al (35) regarding the participation of CAR in the regeneration of damaged myocardial tissue. However, a pro-inflammatory effect mediated by CAR, where the use of immunomodulatory therapy may be important, cannot be excluded [Fig. 3; modified from Ghigo et al (36)].

The evidence of a higher transcriptional level higher transcription of CAR in patients with response to treatment compared with non-responders is of great value, since the expression of this molecule may be a predictive factor in the evolution of the disease and may determine the ability to respond to treatment. Such an observation may also provide physicians with valuable information to facilitate decisions on whether to initiate immunomodulatory pharmacological management, as suggested by Frustaci et al (24).

The sample size of the present study was small, but myocarditis is underdiagnosed, and the results are in line with those of other authors. Another limitation of the present study was that it was impossible to analyze viral persistence in EMB, although this was not a vital part of the study's objective.

In summary, CAR transcription was found to below in the endomyocardial tissue of patients with myocarditis, and it was lower in cases of borderline myocarditis. The CAR mRNA levels were significantly higher in patients responding to therapy versus non-responders. Patients not responding to therapy may present with fewer clinical manifestations, lower CAR transcription levels, and their outcome is less favorable. Thus, it is necessary to investigate differentially the pathophysiological mechanisms involved in such patients. The levels of CAR mRNA may not only be a prognostic factor, but also a tool to guide the pharmacological management of the patient with myocarditis.

\section{Acknowledgements}

The authors would like to thank Dr Armando Mansilla Olivares (Laboratorio de Patología Molecular, Unidad de Investigación Biomolecular, UMAE Hospital de Cardiología del Centro Médico Nacional Siglo-XXI, Instituto Mexicano del Seguro Social, Mexico City, Mexico) and Dr Javier Torres (Unidad de Investigación Médica en Enfermedades Infecciosas y Parasitarias, UMAE, Hospital de Pediatría 'Dr Silvestre Frenk Freund', Centro Médico Nacional Siglo-XXI, Instituto Mexicano del Seguro Social, Mexico City, Mexico) for their invaluable support. They also thank Ms. Erika Cristina de la Peña Cárdenas, designer, for her support with Fig. 3 and Ms. Susan Drier Jonas, for her assistance with the manuscript. The authors would also like to acknowledge the participation of Dr Gustavo Eduardo Garcia Becerril (Clínica de Insuficiencia Cardiaca, UMAE Hospital de Cardiología del Centro Médico
Nacional Siglo-XXI, Instituto Mexicano del Seguro Social, Mexico City, Mexico).

\section{Funding}

The present study was supported by grant FIS/IMSS/PROT/ G15/1466 (to M.G.C.-M.) from the Fondo de Investigación en Salud (FIS)-IMSS, México.

\section{Availability of data and materials}

The datasets used and/or analyzed during the present study are available from the corresponding author on reasonable request.

\section{Authors' contributions}

MGCM and GEGB conceived and designed the experiments. MGCM, AECM, MADLC, MAA, AJGC and CMB performed the experiments. GEGB, AECM and MHGG were invovled in the selection and evaluation of cases. CAFG and LMGJ reviewed the histology data. MGCM, LAMR, AECM and MHGG analyzed the data. MGCM, AECM and MHGG wrote the paper.

\section{Ethics approval and consent to participate}

The present study was approved by the National Research Scientific and Ethics Committee of Instituto Mexicano del Seguro Social (number 17CI09015006 COFEPRIS, Mexico). The study protocol conformed to the principles outlined in the Declaration of Helsinki. All the participants were informed on the nature of the study and provided written consent.

\section{Patient consent for publication}

Patients provided informed consent prior to participation in the present study.

\section{Competing interests}

The authors declare that they have no competing interests.

\section{References}

1. Corsten MF, Schroen B and Heymans S: Inflammation in viral myocarditis: Friend or foe? Trends Mol Med 18: 426-437, 2012.

2. Richardson P, McKenna W, Bristow M, Maisch B, Mautner B, O'Connell J, Olsen E, Thiene G, Goodwin J, Gyarfas I, et al: Report of the 1995 World Health Organization/International Society and Federation of Cardiology Task Force on the definition and classification of cardiomyopathies. Circulation 93: 841-842, 1996.

3. D'Ambrosio A, Patti G, Manzoli A, Sinagra G, Di Lenarda A, Silvestri F and Di Sciascio G: The fate of acute myocarditis between spontaneous improvement and evolution to dilated cardiomyopathy: A review. Heart 85: 499-504, 2001.

4. Global Burden of Disease Study 2013 Collaborators: Global, regional, and national incidence, prevalence, and years lived with disability for 301 acute and chronic diseases and injuries in 188 countries, 1990-2013: A systematic analysis for the Global Burden of Disease Study 2013. Lancet 386: 743-800, 2015.

5. Andréoletti L, Lévêque N, Boulagnon C, Brasselet C and Fornes P: Viral causes of human myocarditis. Arch Cardiovasc Dis 102: 559-568, 2009.

6. Blauwet LA and Cooper LT: Myocarditis. Prog Cardiovasc Dis 52: 274-288, 2010. 
7. Coyne $\mathrm{C}$ and Bergelson J: CAR: A virus receptor within the tight junction. Adv Drug Deliv Rev 57: 869-882, 2005.

8. Cohen CJ, Shieh JT, Pickles RJ, Okegawa T, Hsieh JT and Bergelson JM: The coxsackievirus and adenovirus receptor is a transmembrane component of the tight junction. Proc Natl Acad Sci USA 98: 15191-15196, 2001.

9. Excoffon KJ, Avenarius MR, Hansen MR, Kimberling WJ, Najmabadi H, Smith RJ and Zabner J: The Coxsackievirus and Adenovirus Receptor: A new adhesion protein in cochlear development. Hear Res 215: 1-9, 2006.

10. Bergelson JM, Cunningham JA, Droguett G, Kurt-Jones EA, Krithivas A, Hong JS, Horwitz MS, Crowell RL and Finberg RW: Isolation of a common receptor for Coxsackie B viruses and adenoviruses 2 and 5. Science 275: 1320-1323, 1997.

11. Dorner AA, Wegmann F, Butz S, Wolburg-Buchholz K, Wolburg H, Mack A, Nasdala I, August B, Westermann J, Rathjen FG and Vestweber D: Coxsackievirus-adenovirus receptor (CAR) is essential for early embryonic cardiac development. J Cell Sci 118: 3509-3521, 2005.

12. Kaur T, Mishra B, Saikia UN, Sharma M, Bahl A and Ratho RK Expression of coxsackievirus and adenovirus receptor and its cellular localization in myocardial tissues of dilated cardiomyopathy. Exp Clin Cardiol 17: 183-186, 2012.

13. Ruppert V, Meyer T, Pankuweit S, Jonsdottir T and Maisch B: Activation of STAT1 transcription factor precedes up-regulation of coxsackievirus-adenovirus receptor during viral myocarditis. Cardiovasc Pathol 17: 81-92, 2008.

14. Tatrai E, Bedi K, Kovalszky I, Hartyanszky I, Laszik A, Acsady G, Sotonyi $\mathrm{P}$ and Hubay M: No mutation but high mRNA expression of Coxsackie-Adenovirus Receptor was observed in both dilated and ischemic cardiomyopathy. Forensic Sci Int 212: 47-50, 2011.

15. Ito M, Kodama M, Masuko M, Yamaura M, Fuse K, Uesugi $Y$, Hirono S, Okura Y, Kato K, Hotta Y, et al: Expression of coxsackievirus and adenovirus receptor in hearts of rats with experimental autoimmune myocarditis. Circ Res 86: 275-280, 2000

16. Al-Kofahi M, Omura S, Tsunoda I, Sato F, Becker F, Gavins FNE, Woolard MD, Pattillo C, Zawieja D, Muthuchamy M, et al IL-1 $\beta$ reduces cardiac lymphatic muscle contraction via COX-2 and $\mathrm{PGE}_{2}$ induction: Potential role in myocarditis. Biomed Pharmacother 107: 1591-1600, 2018.

17. Bacmeister L, Schwarzl M, Warnke S, Stoffers B, Blankenberg S, Westermann D and Lindner D: Inflammation and fibrosis in murine models of heart failure. Basic Res Cardiol 114: 19, 2019.

18. Liu Q, Su X, Yu Y and Liu Y: Correlation between virus persistent infection and cardic function in patients with dilated cardiomyopathy. J Zhejiang Univ Sci B 14: 749-753, 2013.

19. Yuen S, Smith J, Caruso L, Balan M and Opavsky MA: The coxsackie-adenovirus receptor induces an inflammatory cardiomyopathy independent of viral infection. J Mol Cell Cardiol 50: 826-840, 2011

20. Liu P, Aitken K, Kong YY, Opavsky MA, Martino T, Dawood F, Wen WH, Kozieradzki I, Bachmaier K, Straus D, et al: The tyrosine kinase p56lck is essential in coxsackievirus B3-mediated heart disease. Nat Med 6: 429-434, 2000.

21. Liu PP and Opavsky MA: Viral myocarditis: Receptors that bridge the cardiovascular with the immune system? Circ Res 86: 253-254, 2000.

22. Niu L, Li C, Wang Z, Xu H and An X: Effects of the MAPK pathway and the expression of CAR in a murine model of viral myocarditis. Exp Ther Med 13: 230-234, 2017.
23. Tschöpe C, Müller I, Xia Y, Savvatis K, Pappritz K, Pinkert S, Lassner D, Heimesaat MM, Spillmann F, Miteva K, et al: NOD2 (Nucleotide-Binding Oligomerization Domain 2) is a major pathogenic mediator of coxsackievirus B3-induced myocarditis. Circ Heart Fail 10, 2017.

24. Frustaci A, Chimenti C, Calabrese F, Pieroni M, Thiene G and Maseri A: Immunosuppressive therapy for active lymphocytic myocarditis: Virological and immunologic profile of responders versus nonresponders. Circulation 107: 857-863, 2003.

25. Aretz HT: Myocarditis: The Dallas criteria. Hum Pathol 18 619-624, 1987.

26. Ponce-Castañeda MV, García-Chéquer AJ, Eguía Aguilar $\mathrm{P}$, Abundes-Ramírez MA, Hernández-Angeles A, Nieto-Martínez K, Gómez-Laguna L, Sadowinski-Pine S and Cabrera-Muñoz Mde L: Detection of common chromosomal translocations in small round blue cell pediatric tumors. Arch Med Res 45: 143-151, 2014.

27. Jahn CE, Charkowski AO and Willis DK: Evaluation of isolation methods and RNA integrity for bacterial RNA quantitation. J Microbiol Methods 75: 318-324, 2008.

28. Aranda PS, LaJoie DM and Jorcyk CL: Bleach gel: A simple agarose gel for analyzing RNA quality. Electrophoresis 33: 366-369, 2012.

29. Pfaffl MW: A new mathematical model for relative quantification in real-time RT-PCR. Nucleic Acids Res 29: e45, 2001.

30. Livak KJ and Schmittgen TD: Analysis of relative gene expression data using real-time quantitative PCR and the 2(-Delta Delta C(T)) method. Methods 25: 402-408, 2001.

31. Hufnagel G, Pankuweit S, Richter A, Schönian U and Maisch B: The European study of epidemiology and treatment of cardiac inflammatory diseases (ESETCID). First epidemiological results. Herz 25: 279-285, 2000.

32. Aretz HT, Billingham ME, Edwards WD, Factor SM, Fallon JT, Fenoglio JJ Jr, Olsen EG and Schoen FJ: Myocarditis. A histopathologic definition and classification. Am J Cardiovasc Pathol 1: 3-14, 1987.

33. Lieberman EB, Hutchins GM, Herskowitz A, Rose NR and Baughman KL: Clinicopathologic description of myocarditis. J Am Coll Cardiol 18: 1617-1626, 1991.

34. Angelini A, Crosato M, Boffa GM, Calabrese F, Calzolari V, Chioin R, Daliento L and Thiene G: Active versus borderline myocarditis: Clinicopathological correlates and prognostic implications. Heart 87: 210-215, 2002.

35. Noutsias M, Fechner H, de Jonge H, Wang X, Dekkers D, Houtsmuller AB, Pauschinger M, Bergelson J, Warraich R, Yacoub M, et al: Human coxsackie-adenovirus receptor is colocalized with integrins alpha(v)beta(3) and alpha(v)beta(5) on the cardiomyocyte sarcolemma and upregulated in dilated cardiomyopathy: Implications for cardiotropic viral infections. Circulation 104: 275-280, 2001.

36. Ghigo A, Franco I, Morello F and Hirsch E: Myocyte signalling in leucocyte recruitment to the heart. Cardiovasc Res 102: 270-280, 2014.

This work is licensed under a Creative Commons Attribution-NonCommercial-NoDerivatives 4.0 International (CC BY-NC-ND 4.0) License. 